\title{
Cervicoplastia na flacidez cutânea por síndrome de Ehlers-Danlos: relato de caso
}

\section{Cervicoplasty in cutaneous laxity from Ehlers-Danlos syndrome: a case report}

\author{
Márcio Rocha Crisóstomo ${ }^{1}$ \\ Victor José Timbó Gondim ${ }^{2}$ \\ André Nunes Benevides 3 \\ Mara Rocha Crisóstomo ${ }^{2}$ \\ Salustiano Gomes de \\ Pinho Pessoa
}

Trabalho realizado no Serviço de Cirurgia Plástica e Microcirurgia Reconstrutiva do Hospital Universitário Walter Cantídio, Fortaleza, CE, Brasil.

Aartigo submetido pelo SGP (Sistema de Gestão de Publicações) da RBCP.

Artigo recebido: 28/6/2009 Artigo aceito: 18/9/2009

\begin{abstract}
RESUMO
Introdução: A síndrome de Ehlers-Danlos é um distúrbio raro, caracterizado por anormalidades diversas na estrutura, síntese e secreção do colágeno, resultando em um quadro clínico variado, com alterações cutâneas, articulares e vasculares. Procedimentos cirúrgicos realizados nestes pacientes, muitas vezes, complicam com sangramentos de difícil controle, deiscência de suturas, friabilidade dos tecidos, hematomas recorrentes e dificuldade de cicatrização, com pobres resultados estéticos. Relato do caso: No presente relato, os autores apresentam um caso de cervicoplastia em paciente portadora da síndrome de Ehlers-Danlos, evidenciando seus resultados.
\end{abstract}

Descritores: Síndrome de Ehlers-Danlos. Cervicoplastia. Pseudoxantoma elástico.

\section{SUMMARY}

Introduction: The Ehlers-Danlos syndrome is a rare disorder characterized by multiples anomalies in collagen synthesis, structure and secretion, resulting in innumerous clinical manifestations such as cutaneous, articular and vascular abnormalities. Surgical procedures are often complicated by difficulty in control bleeding, wound dehiscence, tissue friability, recurrent hematomas and problems in wound healing, leading to poor aesthetic results. Case report: In the present report, the authors present a case of cervicoplasty in a patient with Ehlers-Danlos syndrome, exposing their results.

Descriptors: Ehlers-Danlos syndrome. Cervicoplasty. Pseudoxanthoma elasticum.

\section{INTRODUÇÃO}

A síndrome de Ehlers-Danlos (SED) abrange um grupo de desordens clínicas e genéticas do tecido conjuntivo, envolvendo múltiplos órgãos, pele, vasos e articulações ${ }^{1,2}$. É um distúrbio raro, com incidência de 1 caso para cada 5.000 nascimentos, que afeta igualmente homens e mulheres de todas as raças e etnias ${ }^{1}$.

Hipócrates, em 400 a.C., foi o provável descobridor da doença ${ }^{3}$. Esta ganhou nome após os relatos dos dermatologistas Edvard Ehlers, dinamarquês, e Henri Danlos, francês, que em 1899 e 1908, respectivamente, apresentaram casos de pacientes com subluxações de joelhos, lesões e frouxidões articulares, além de hiperextensibilidade cutânea ${ }^{1-4}$.
$\mathrm{Na}$ fisiopatologia da SED há uma anormalidade na síntese do colágeno, com defeitos tanto neste processo quanto na estrutura e na secreção dessa proteína ${ }^{5}$. As fibras de colágeno na derme podem estar desorganizadas e as fibras elásticas apresentam irregularidades no tamanho e na orientação ${ }^{4}$.

Há seis diferentes tipos de SED, cuja classificação foi baseada em critérios clínicos, genéticos e bioquímicos. Os sintomas mais comuns são: hiperextensibilidade cutânea, com consequente flacidez e vulnerabilidade a traumatismos, cicatrização atrófica e hipermobilidade articular. Pode haver também formação de aneurismas, hematomas e ruptura de ligamentos articulares, complicações estas presentes de acordo com o tipo ${ }^{2,6}$.

\footnotetext{
1. Preceptor colaborador do Serviço de Cirurgia Plástica e Microcirurgia Reconstrutiva do Hospital Universitário Walter Cantídio (HUWC) da Universidade Federal do Ceará (UFC); Membro titular da Sociedade Brasileira de Cirurgia Plástica (SBCP), Mestre em Cirurgia pela UFC.

2. Médico(a) formado pela UFC.

3. Membro da Liga de Cirurgia Plástica e Microcirurgia Reconstrutiva Dr. Germano Riquet; Acadêmico de Medicina da UFC.

4. Regente do Serviço de Cirurgia Plástica e Microcirurgia Reconstrutiva do HUWC / UFC; Membro titular da SBCP.
} 
Não há cura para a síndrome; o manejo da SED envolve basicamente suporte (psicoterapia e reabilitação) e prevenção de complicações ${ }^{6}$. A cirurgia plástica pode diminuir as alterações estéticas decorrentes do excesso cutâneo.

O objetivo deste artigo é relatar a correção cirúrgica de flacidez cervical em uma paciente com SED e fazer uma breve revisão de literatura.

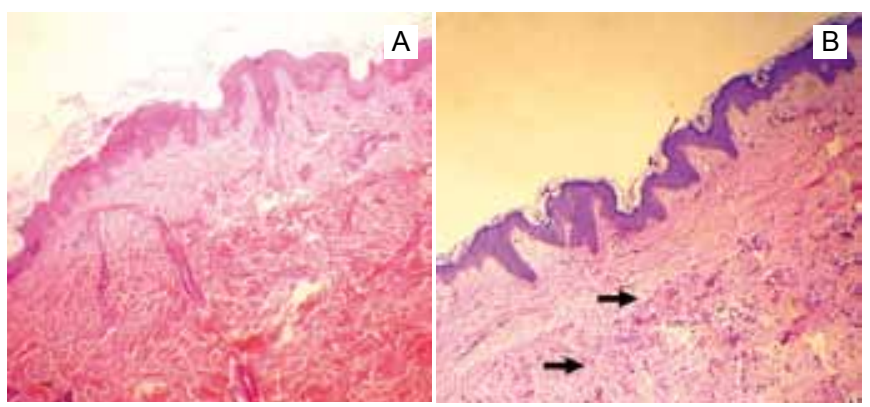

Figura 1 - A: corte histológico de pele normal; B: biopsia cutânea da paciente, demonstrando desorganização difusa do colágeno na derme profunda (setas),

\section{RELATO DO CASO}

Paciente do sexo feminino, 28 anos, casada, com queixa de acentuada flacidez em região cervical em evolução há 10 anos. Ao exame, comprovou-se importante alteração de elasticidade na referida localização e em região axilar. Apresentava diagnóstico histológico de síndrome de EhlersDanlos (Figura 1).

Foi realizado tratamento cirúrgico sob anestesia local (infiltração de solução de xilocaína ${ }^{\circledR}$ com adrenalina 1:200.000), associada à sedação venosa. Efetuou-se a cervicoplastia com incisão retroauricular e pré-pilosa posterior, seguida de descolamento da região cervical até o submento, tração posterior da pele, plicatura do sistema músculoaponeurótico superficial - platisma lateral e ressecção do excesso cutâneo. A síntese foi feita em dois planos, sutura subdérmica com fio monocryl ${ }^{\circledR}$ 4-0 e sutura externa com mononylon ${ }^{\circledR}$ 5-0 (Figura 2). Não houve qualquer intercorrência durante o ato operatório.

A paciente evoluiu sem complicações, com satisfação em relação aos resultados (Figura 3).

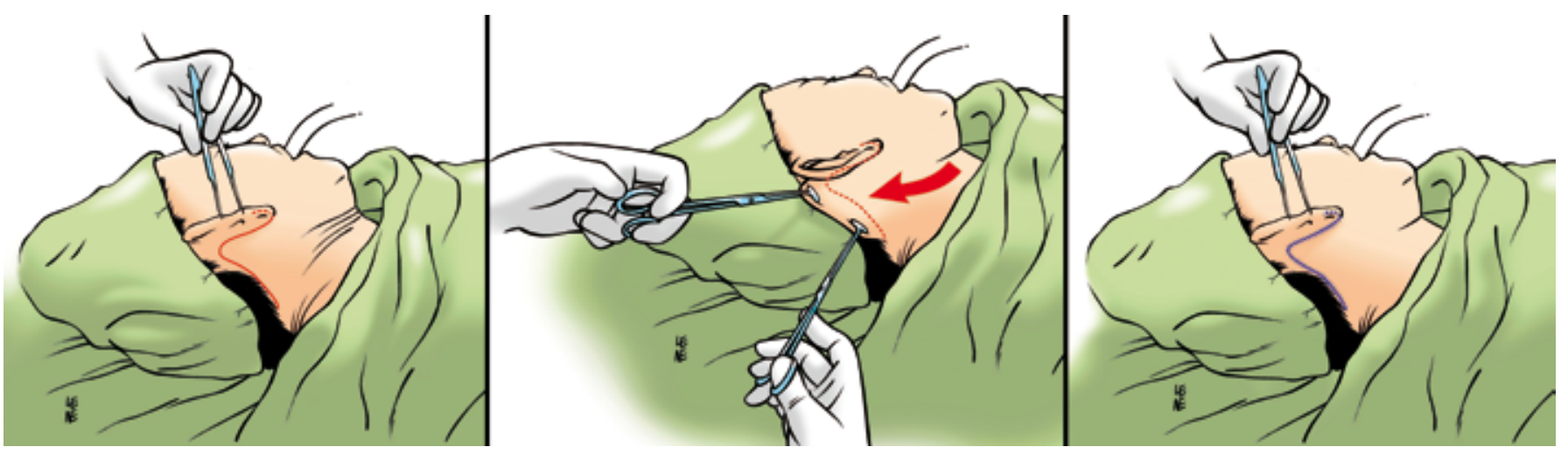

Figura 2 - Desenho esquemático da técnica cirúrgica.
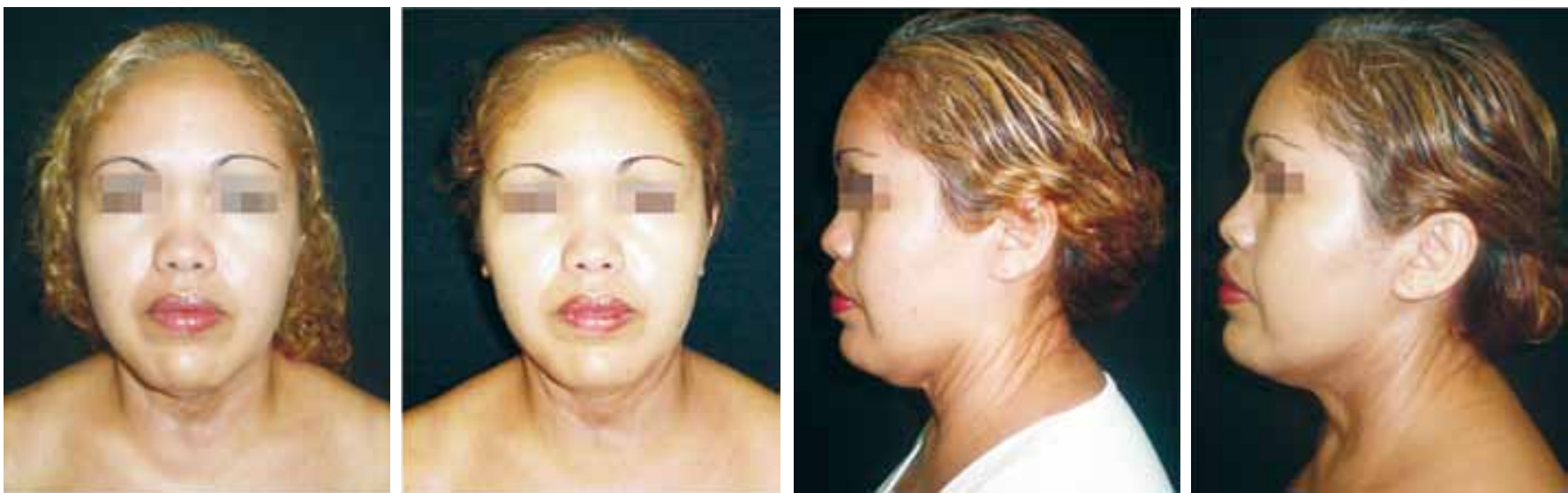

Figura 3 - Pré e pós-operatório de 8 meses. 


\section{DISCUSSÃO}

As alterações do colágeno presentes na SED conferem uma resistência anormal à tração, gerando, além da debilidade cutânea, uma fragilidade capilar importante, o que, durante o ato cirúrgico, pode causar sangramentos de difícil controle $^{3,7-10}$. Embora sejam frequentes os relatos de sangramentos assim característicos, nesta paciente não foi observada tal intercorrência. Anormalidades hematológicas, como alterações plaquetárias e em fatores de coagulação também são reportadas ${ }^{6}$. A incidência de deiscência da sutura também está aumentada, levando à necessidade de uma tensão menor nos pontos ${ }^{3,10}$. Há também relatos de hiperpigmentação, alargamento e adelgaçamento da cicatriz, o que também não ocorreu nessa paciente ${ }^{3,9,10}$. Essas peculiaridades podem prejudicar o resultado estético ${ }^{3,5,6}$. Guerrerosantos e Dicksheet $^{7}$, em um relato de caso semelhante, citam complicações como hematomas recorrentes no pós-operatório, deiscência da incisão retroauricular e aspecto inaceitável desta cicatriz, intercorrências não observadas pelos autores do presente relato.

A SED envolve diversos aspectos psicossociais, incluindo problemas de autoestima, ansiedade e depressão ${ }^{2}$. O procedimento cirúrgico se torna uma importante ferramenta no papel de minimizar esses efeitos. Apesar das dificuldades técnicas inerentes à síndrome, o caso relatado não apresentou intercorrências ou complicações e o resultado estético foi considerado satisfatório pela paciente e pelo cirurgião. A evolução deste caso mostra que a cirurgia, quando bem indicada, pode ser realizada em pacientes com SED, com bons resultados.

\section{REFERÊNCIAS}

1. Lawrence EJ. The clinical presentation of Ehlers-Danlos syndrome. Adv Neonatal Care. 2005; 5(6): 301-14.

2. Berglund B, Nordström G. Symptoms and functional health status of individuals with Ehlers-Danlos Syndrome (EDS). J Clin Rheumatol. 2001; 7(5): 286-7.

3. Pitanguy I, Torres CM. Síndrome de Ehlers-Danlos. Rev Bras Cir. 1976; 66(11/12): 395-400.

4. Steinmann B, Royce PM, Superti-Furge A. The Ehlers-Danlos syndrome. In: Royce PM, Steinmann B, editores. Connective tissue and its heritable disorders. New York: Wiley-Liss; 1993. p. 351-407.

5. Abbas AK. Doenças genéticas. In: Kumar V, Abbas AK, Fausto N, editores. Patologia - bases patológicas das doenças. Rio de Janeiro: Guanabara Koogan; 2005. p. 153-203.

6. Hamel BCJ. Ehlers-Danlos syndrome. Neth J Med. 2004; 62(5): 140-2.

7. Anstey A, Wilkinson JD, Pope FM. Ehlers-Danlos syndrome with recurrent bruising. J R Soc Med. 1990; 83(12): 800-1.

8. Guerrerosantos J,DicksheetS.Cervicofacialrhytidoplasty inEhlers-Danlos syndrome: hazards on healing. Plast Reconstr Surg. 1985; 75(1): 100-3.

9. Sharma NL, Mahajan VK, Gupta N, Ranjan N, Lath A. Ehlers-Danlos syndrome - vascular type (ecchymotic variant): cutaneous and dermatopathologic features. J Cutan Pathol. 2009; 36: 486-92.

10. Girotto JA, Malaisrie SC, Bulkely G, Manson PN. Recurrent ventral herniation in Ehlers-Danlos syndrome. Plast Reconstr Surg. 2000; 106(7):1520-6.

\section{Correspondência para:}

Márcio Rocha Crisóstomo

Avenida Dom Luís, 1233, $21^{\circ}$ andar - Meireles - Fortaleza, CE, Brasil - CEP: 60160-230

E-mail: marcio@clin.med.br 